\title{
Epidemiology and the Macrosocial Determinants of Health
}

\author{
SARA PUTNAM ${ }^{1}$ and SANDRO GALEA ${ }^{1,2,3}$ \\ ${ }^{\mathrm{I}}$ Center for Urban Epidemiologic Studies, New York Academy of Medicine, \\ New York, NY, USA; \\ ${ }^{2}$ Center for Social Epidemiology and Population Health, Department of \\ Epidemiology, University of Michigan School of Public Health, Ann Arbor, \\ MI, USA; \\ ${ }^{3}$ Department of Epidemiology, Columbia University Mailman School of Public \\ Health, New York, NY, USA
}

Correspondence: Sandro Galea, MD, DrPH, Department of Epidemiology, University of Michigan, School of Public Health, $\mathrm{I}_{21}$ S. University, Ann Arbor, MI 48 1०4, USA. E-mail: sgalea@umich.edu

\begin{abstract}
In the past two decades, public health researchers have taken renewed interest in investigating the role of social factors in health. This holds substantial promise in terms of identifying manipulable social factors that are amenable to policy intervention. Most existing empirical and conceptual epidemiologic work, however, has focused on the more proximal social determinants, such as interpersonal relations. These factors, although perhaps easier to study epidemiologically, are much less relevant to policy makers than more "macrosocial" factors such as taxation policies. Limited epidemiologic attention to macrosocial determinants of health is ironic given that macrosocial factors such as the rapid industrialization and urbanization in the 19 th century contributed to the organization of public health practice and, tangentially, to academic public health research. We suggest here that greater investment in the study of macrosocial determinants has the potential to make a significant and unique contribution to the greater public health agenda and should be a prominent aspect of social epidemiologic inquiry in the coming decades.
\end{abstract}

Journal of Public Health Policy (2008) 29, 275-289.

doi:10.1057/jphp.2008.I 5

Keywords: social determinants, public health, epidemiologic methods

\section{EPIDEMIOLOGY AND THE MACROSOCIAL DETERMINANTS OF HEALTH}

Social circumstances that give rise to health and disease have long been a concern of public health research and practice (I-5). 亲 Journal of Public Healtb Policy 2008, 29, 275-289 (C) 2008 Palgrave Macmillan Ltd or 97-5897/08 
Although the dominant paradigm for much of the mid-2oth century, risk-factor epidemiology, focused largely on individual behaviors and traits, in the past two decades, public health researchers have taken renewed interest in investigating the role of social factors in health. The growth in recent years of increasingly sophisticated research on social factors is indicative of the genuine interest within public health in the role that social factors play in determining health and disease.

This development in epidemiologic research holds particular promise for health policy. Social factors may be manipulable through policy intervention, suggesting that social epidemiology can provide the evidence that can inform policy development. From a policy point of view, however, not all social factors are of equal interest. Social factors at the individual level (or "downstream" or "micro"social determinants), such as inter-individual relationships and personal networks, are frequently quite far from the policy makers' level of influence and, as such, are of relatively limited interest to health policy. By contrast, social factors at the population level (or "upstream" or "macro"-social determinants), such as taxation practices, zoning laws, or economic policies, concern processes that are of day-to-day concern for policy makers. Thus, evidence for the role of macrosocial factors in shaping health may well usefully inform the development of healthier public policy.

Unfortunately, we suggest here that most social epidemiology to date has focused on more microsocial determinants, and thereby the promise of social epidemiology as a useful tool for informed policy making has not yet been fully realized. In this essay, we describe the current approach to social determinants of health research, discuss the merits of a more upstream perspective on social determinants as well as reasons why it has been underexamined to date, and propose ways in which epidemiologists and policy makers can use existing frameworks as a starting point for expanding inquiry into macrosocial determinants of population health.

SOCIAL DETERMINANTS OF HEALTH

Modern "social epidemiology" emerged first from proponents of social medicine, who argued for greater consideration of social 
factors in disease determination (6-12). As this movement was gaining traction in the I990s, Link and Phelan (13) described socioeconomic status, social networks, and stigmatization as "fundamental causes" of disease. Link and Phelan maintained that these factors shape access to significant salutary resources that ultimately influence health, such as money, knowledge, power, prestige, and social support. They suggested that fundamental causes can affect health through multiple mechanisms and are not diseasespecific. Further, as root causes, these factors continue to influence health regardless of the effectiveness of individual treatment or therapy. Even as knowledge about healthy behavior increases and as effective individual treatments improve, populations characterized by socioeconomic disadvantage will always lag behind in their adoption of these health-generating behaviors and resources, resulting in persistent socioeconomic disparities in health (14).

The work of these and many other authors contributed to greater attention to the role of social causation in public health as research concerning such social factors as gender, (e.g., Perry (15)), race/ ethnicity (e.g., Baltrus et al. (I6)), discrimination (e.g., Krieger (I 7); Williams (I8)), occupational conditions (e.g., Lallukka et al. (19)), socioeconomic status (e.g., Kanjilal et al. (2o)), and education (e.g., Jacobsen and Thelle (2I)), proliferated. Important observations with significant societal implications have resulted from these studies. For example, the relationship between income and health, namely that persons with lower income have greater disease morbidity and higher age-adjusted mortality than persons with higher income, may well be one of the best documented relationships in public health and epidemiology $(22,23)$.

However, most existing empirical and even conceptual work has centered on the more downstream social determinants. For instance, although ample literature has suggested that stigmatizing behavior may be an important determinant of mental health $(24-26)$, the question of why certain populations are characterized by greater or lesser stigmatizing practices has received much less attention. Given the potential for research at this level to contribute to the overarching goal of health promotion and disease prevention, the dearth of epidemiologic inquiry into upstream social determinants of population health is a significant shortcoming of the extant literature. 
Macrosocial determinants of health are those upstream social factors ranging from culture and belief systems, to corporate practices, political ideologies, and economic philosophies at local and national levels. Macrosocial forces also shape more downstream social characteristics. For example, there is an emerging literature that income inequality is associated with adverse health, independent of absolute levels of income (27-30). Therefore, at the macro-level, we can imagine how population distributions of income are influenced by global as well as national political and economic priorities, manifested in tax regulations, distribution mechanisms and policies, as well as institutionalized racism and gender or class exploitation. An understanding of how these forces interact to shape population health would have enormous policy implications. However, there are few epidemiologic investigations of these relationships.

Many of the early voices and arguments for greater macrosocial thinking were subsumed within the debates over the limitations of "individualization" of epidemiologic thinking that reached fever pitch in the mid-1990s (3I). Disputes centered on the merits of investigation of the various "causes" of health outcomes (social forces, individual lifestyles, or genes and molecular agents) at the various levels of analysis (population, individual, and molecular). Out of these shifting sands emerged multilevel, theoretical frameworks of disease production, some integrating historical context and a life-course perspective $(9,32,33)$.

Kaplan (34) proposed, for example, that factors including globalization of the economy, deforestation, lack of social resources, high stress, and low real wages contribute to cardiovascular disease. $\mathrm{He}(33)$ and others $(32,35-42)$ have long noted that social, political, environmental, and economic structures or processes influence and interact with downstream social factors and conditions to affect health. Others, too, have encouraged study of "sociopolitical," "socioeconomic," "societal," "global," "upstream," "ultimate," "structural," or "macro" factors and their effect on health $(31,32$, $34,35,39,40,42-44)$. Established multilevel epidemiologic perspectives such as eco-epidemiology (45) and eco-social theory (9) also would seem to necessitate their integration into any understanding of health. Further, under the leadership of Sir Michael Marmot, the 
World Health Organization's Commission on the Social Determinants of Health has recently proposed a thoughtfully articulated framework for considering the production of disease through a welldelineated hierarchy of social causes $(46)$.

These frameworks underline the interdependence of factors at all levels in the production of health and disease, thereby highlighting the relevance of analysis at each of these levels either singly or in multi-level models. Indeed, we seek not to subvert these models, but, in line with their egalitarian emphasis, to bring attention again to macrosocial determinants as an under-studied area, one that has potential for significant contribution to the public health policy agenda.

BARRIERS AND RESERVATIONS FOR EPIDEMIOLOGY

The limited attention that has been given to macrosocial determinants of health is ironic given that macrosocial factors such as the rapid industrialization and urbanization in the 19 th century contributed to the organization of public health practice, and less directly to academic public health research (47). We suggest that the scarcity of research in the area is a reflection of four primary factors.

First, the appreciation of macrosocial determinants as topics of consideration within the realm of public health is relatively new to modern public health researchers and practitioners. Current epidemiologists may feel under-prepared to face such questions without cross-disciplinary training. Rothman et al. (48) argued that epidemiologists should not be expected to solve problems that are beyond their expertise, suggesting that applying epidemiologic methods to macroeconomic questions, for instance, is straying into the domain and even challenging the expertise of economists. Rothman et al. (48) support the ideals behind studying macrosocial determinants, but suggest that it may be beyond the scope of public health research and practice. Poole and Rothman (49) also raise the question of whether studies for which disease occurrence is not the outcome of interest - studies that look at how macro-level factors shape mid-level determinants - can be classified as epidemiologic. Given that a core function of public health activities is to improve health and prevent disease, we argue that epidemiologists must be participating in explorations of how macrosocial factors interact 
with proximal factors. This knowledge is a critical component in designing meaningful interventions. To reiterate, understanding why a population has a certain degree of income inequality is inextricably linked to the consideration of efforts to mitigate the influence of income inequality on population health.

Second, it has been suggested that a greater focus on macrosocial determinants would open the door to criticisms that epidemiology is no longer an objective science, but a platform for the promotion of political beliefs and agendas ( 50 ). Interestingly, this perspective may itself be reflective of the influence of macrosocial determinants Western belief systems center on individual rights over collective interests ( $\mathbf{I}_{3}$ ). This underscores the argument that causal theories are inextricably linked to systems of values and ideology, and the essential requirement for transparency and interpretation of research is that these values be explicit $(5 \mathrm{I})$. Thus, expanding inquiries to more upstream macrosocial factors does not in itself pose a threat to objectivity, but rather offers an opportunity for improvement, as more perspectives can be considered, understood, and evaluated on their comparative merits. Further, the epidemiologic community is a peer group of trained scientists for whom ethical standards are explicit and expected; researchers can, do, and will police the contributions made to the body of knowledge.

Third, macrosocial determinants have remained relatively unexamined because they influence the health of whole populations over and above individual characteristics and relations. Thereby, they lend themselves to population level rather than individual level health studies. The term "population" refers to whole groups of persons, be they groups within neighborhoods, occupational class, or other levels of aggregation. A population health strategy aims to identify common underlying causes of disease for whole populations (52). Although epidemiology and public health had origins in population health (I5), modern research tends to concentrate on individual-level risk factors for disease. Epidemiologists have expressed concerns about interpreting population-level data (e.g., ecologic and sociologistic fallacies). Rothman et al. (48) are concerned that "the further upstream we move from the occurrence of disease towards root causes, the less secure our inferences about the causal path to disease become." At the same time, existing individual-level efforts to improve health have not generally proven 
successful, and population strategies may be what is necessary for meaningful change. Additionally, existing statistical methods are more appropriate for interpretation at the population level $(5 \mathrm{I})$. Social epidemiology and population health have obvious synergy in the study of group-level contextual variables (means, proportions, and measures of dispersion) and variables that do not have analogs at the individual level (e.g., regulations, availability, and political systems) (33).

Fourth, the commonly used research methods within public health (including both quantitative and qualitative methods) are limited in considering how macrosocial factors shape the health of populations. The dominant epidemiologic-methodologic paradigm, for example, makes use of linear mathematical models that embed substantial assumptions about independence of key predictors. It is likely, however, that macrosocial factors do not influence health in a linear fashion and that more complex methods are needed to explain the relationship between these factors and population health. Throughout history, flexibility has characterized science-advancing knowledge and meeting new challenges. Epidemiology's own methods have been continually refined and advanced $(53,54)$. Thus, epidemiologists must view the complex interactions of macrosocial determinants as a challenge to be met rather than an obstacle to evade.

\section{PROMISING DIRECTIONS}

Some forays into empirical work serve as examples of where macrosocial inquiry can begin. The relationship of political economy - political decisions about resource distribution - to population health, for instance, has been the subject of examination in the past (55) and recently $(56,57)$. Political decisions about resource distribution have been shown to influence the distribution of health via intermediary social determinants (57). The journal Globalization and Health $(58)$ was launched in 2005 , its primary aim to publish studies that assess the health impacts of factors that transcend geopolitical boundaries.

Interest in macrosocial health effects related to corporate practices has grown and lately come under increasingly intense scrutiny by policy makers, consumer watchdogs, health professionals, and even 
the general public. Policy-level responses to health risks such as tobacco use and unhealthy food consumption are obvious examples of this trend. Cities and countries around the world have increased taxes on cigarette sales; San Francisco and New York City have regulated trans-fat in restaurants, and others have proposed rules requiring chain restaurants to display caloric content on menus and menu boards. These developments, frequently the result of partnerships between policy makers and local health departments, may serve as models for others working at the macrosocial level to improve population health outcomes.

Of course, public health policy should be - and hopefully is based on epidemiologic evidence at the population level. The corporate practices literature yields some insight into how macrosocial factors can be conceptualized and studied. Nicholas Freudenberg and one of us (Galea) (59) have proposed a conceptual framework for analysis of how corporate practices affect health. Four corporate activities may harm health: production and design, marketing, retail distribution, and pricing. Empirical research about corporate practices includes studies of youth-targeted advertising of tobacco $(60,61)$, low-nutrient foods $(62)$, and higher concentrations of alcohol retail outlets in low-income or minority neighborhoods (63). Other researchers have studied the health effects of political responses to unhealthy - but legal - products; examples include taxation of tobacco products (64) and smoking bans (65). Even more can and should be done to understand the health impact of these industries' practice, as well as societal responses. The existing body of literature, however, highlights the dearth of systematic investigations for other industries - not to mention other macrosocial factors. Indeed, the opportunities for macrosocial research should serve as a siren call for epidemiologists interested in improving population health.

With, for the first time in history (66), more than half of the world's population residing in urban areas, the effect of urbanization and local conditions on urban and migrant populations may be one important frontier to explore. Multilevel studies that include contextual variables are often limited to the neighborhood level, yet inquiry directed at municipal levels might yield rich insights with important population health implications. As much research has been conducted on health impacts of the built environment, 
PUTNAM AND GALEA - MACROSOCIAL DETERMINANTS OF HEALTH $\mathbf{2 8 3}$

partnerships between urban planners, and city councils, and epidemiologists seem the next logical step to ensure that development plans are truly mindful of the health and well-being of the populace.

In volume 35 issue 2 of the International Journal of Epidemiology, its editor, George Davey Smith, suggested that the featured research papers and editorials focusing on "collectively experienced" macrosocial factors of the physical and cultural climate were a pleasant departure from the usual content of the journal (67). We believe further exploration of these and other macrosocial factors are warranted and necessary to improve overall population health. For that reason, work on macrosocial determinants must no longer be the exception to the "mundane,"(67) ordinary work of epidemiologists, but a viable and vibrant area of study.

\section{CHALLENGES AHEAD}

Undertaking analyses of macrosocial determinants of population health will require a substantial intellectual investment and will undoubtedly stretch the imaginations and practical capacities of epidemiologists and policy makers alike. Social epidemiologic methods are still nascent, and there is no question that a systematic consideration of macrosocial determinants of population health will require refinement of current methods, development of new methods, and judicious and careful interpretation of study results. Public health stands to benefit greatly from cross-disciplinary communication and collaboration. Insights from many disciplines, including economics, sociology, anthropology, ethnography, demography, and health policy, among many others, play a critical role in understanding and addressing macrosocial determinants of population health. Indeed, experts from such disciplines should be invited to collaborate and advise in epidemiologic studies attempting to elucidate these determinants.

Although epidemiologists have an obvious role to play in rectifying the gap in the public health knowledge base around macrosocial determinants, policy makers must also take the initiative to offer a receptive environment for this type of work. Given how research funding drives academic and public health inquiry, macrosocial determinants of population health thinking will need 
to make substantial inroads into funding institutions, traditionally biomedical-oriented. Thus, there is a clear need for priorities and incentives to be realigned at the policy level.

Change in public health, as in all human endeavors, comes slowly. Questions about how globalization has influenced population rates of heart disease reflect, for example, a substantial departure from most modern public health literature that continues to influence and shape the work we all do. However, we have little doubt that with time, public health practitioners will find suitable ingenuity, insight, and imagination to develop and advance the field.

\section{ABOUT THE AUTHORS}

Sara Putnam was a project manager at the Center for Urban Epidemiologic Studies at the New York Academy of Medicine when this manuscript was written. She is currently with the New York City Department of Mental Health and Hygiene.

Sandro Galea is an associate professor of Epidemiology at the University of Michigan School of Public Health. He is also an adjust associate professor at the Columbia University Mailman School of Public Health and a fellow of the New York Academy of Medicine.

\section{REFERENCES}

I. Ackernecht EH. Rudolf Virchow: Doctor, Statesman, Anthropologist. Madison, WI: University of Wisconsin Press; 1953.

2. Berkman LF, Glass T, Brissette I, Seeman TE. From social integration to health: Durkheim in the new millennium. Soc Sci Med. 2000; 5I(6):843-57.

3. Coleman W. Death is a Social Disease: Public Health and Political Economy in Early Industrial France. London: University of Wisconsin Press; 1982.

4. Engels F. The Condition of the Working Class in England. First published, Germany, 1845. English translation first published in I 886; republished with some revisions, and edited by Victor Kiernan. New York, NY: Penguin Books; 1987.

5. Hamlin CS. The history of methods of social epidemiology to 1965 . In: Oakes JM, Kaufman JS, editors. Methods in Social Epidemiology. San Francisco: John Wiley \& Sons, Inc; 2006, pp. 2 I-44. 
6. Berkman LF, Kawachi I. A historical framework for social epidemiology. In: Berkman LF, Kawachi I, editors. Social Epidemiology. New York: Oxford University Press; 2000.

7. Cassel J. The contribution of the social environment to host resistance: the fourth Wade Hampton Frost lecture. 1976. Am J Epidemiol. 1995;104:107-23.

8. Galdston I. Social medicine; Its Derivations and Objectives. New York: Commonwealth Fund; I949.

9. Krieger N. Theories for social epidemiology in the 2 Ist century: an ecosocial perspective. Int J Epidemiol. 2001;30:668-77.

Io. Syme SL. Historical perspective: the social determinants of disease - some roots of the movement. Epidemiologic Perspectives Innovations. 2005;2(2).

I I. Marmot MG. Stress, social and cultural variations in heart disease. J Psychosom Res. 1983;27(5):377-84.

I 2. Marmot M. Socioeconomic determinants of CHD mortality. Int J Epidemiol. 1989;18(3 Suppl I):SI96-202.

I 3. Link BG, Phelan J. Social conditions as fundamental causes of disease. J Health Soc Behav. 1995; Extra Issue: 80-94.

14. Geronimus AT. To mitigate, resist or undo: addressing structural influences on health.... Am J Public Health. 2000;90(6):867-87 I.

I 5. Szreter S. The population health approach in historical perspective. Am J Public Health. 2003;93(3):42 I-3 I.

16. Baltrus PT, Lynch JW, Everson-Rose S, Raghunathan TE, Kaplan GA. Race/ethnicity, life-course socioeconomic position, and body weight trajectories over 34 years: the Alameda County Study. Am J Public Health. 2005;95(9): 1 595-601.

17. Krieger N. Discrimination and health. In: Berkman L, Kawachi I, editors. Social Epidemiology. New York: Oxford University Press; 2000.

I8. Williams DR. Race, socioeconomic status, and health. The added effects of racism and discrimination. Ann NY Acad Sci. 1999;896: I 73-188.

I9. Lallukka T, Martikainen P, Reunanen A, Roos E, Sarlio-Lahteenkorva $\mathrm{S}$, Lahelma E. Associations between working conditions and angina pectoris symptoms among employed women. Psychosom Med. 2006; (2):348-54.

20. Kanjilal S, Gregg EW, Cheng YJ, Zhang P, Nelson DE, Mensah G, et al. Socioeconomic status and trends in disparities in 4 major risk factors for cardiovascular disease among US adults, 1971-2002. Arch Intern Med. 2006;166(2I):2348-55.

21. Jacobsen BK, Thelle DS. Risk factors for coronary heart disease and level of education. The Tromso Heart Study. Am.J.Epidemiol. I $988 ; 127(5): 923-32$. 
22. Adler NE, Marmot M, McEwen BS, Stewart S. Socioeconomic Status and Health in Industrial Nations. New York City, NY: New York Academy of Sciences; 1999.

23. Kawachi I, Kennedy BP, Wilkinson RG, editors. The Society and Population Health Reader: Income Inequality and Health. New York: The New Press; 1999.

24. Lindström M. Social capital, anticipated ethnic discrimination and self-reported psychological health: a population-based study. Soc Sci Med. 2008;66(I):I-I3. Epub 4 September 2004.

25. Stuber J, Galea G, Ahern J, Blaney S, Fuller C. The association between multiple domains of discrimination and self-assessed health: a multilevel analysis of Latinos and Blacks in four low-income neighborhoods. Health Serv Res. 2003;38(6):1735-59.

26. Mays VM, Cochran SD. Mental health correlates of perceived discrimination among lesbian, gay, and bisexual adults in the United States. Am J Public Health. 2001;91(1 I):1869-76.

27. Subramanian SV, Kawachi I. Whose health is affected by income inequality? A multilevel interaction analysis of contemporaneous and lagged effects of state income inequality on individual self-rated health in the United States. Health Place. 2006;12(2):141-56. Epub I 8 January 2005.

28. Lynch J, Harper S, Kaplan GA, Davey Smith G. Associations between income inequality and mortality among US states: the importance of time period and source of income data. Am J Public Health. 2005;95(8):1424-30. Epub 7 July 2005.

29. Subramanian SV, Kawachi I. The association between state income inequality and worse health is not confounded by race. Int J Epidemiol. 2003;32(6):1022-8.

30. Wolfson M, Kaplan G, Lynch J, Ross N, Backlund E. Relation between income inequality and mortality: empirical demonstration. $B M J$. 1999;3 19(7215):953-5.

3I. Pearce N. Traditional epidemiology, modern epidemiology, and public health. Am J Public Health. 1996;86(5):678-83.

32. McMichael AJ. Prisoners of the proximate: loosening the constraints on epidemiology in an age of change. Am J Epidemiol. 1999;149(10): $887-97$.

33. Diez-Roux AV. Bringing context back into epidemiology: variables and fallacies in multilevel analysis. Am J Public Health. 1998;88(2): 217-223.

34. Kaplan GA. What's wrong with social epidemiology, and how can we make it better? Epidemiol Rev. 2004;26:124-35. 
35. Commission on the Social Determinants of Health. A Conceptual Framework for Action on the Social Determinants of Health. Geneva: World Health Organization; 2007.

36. Galea S, Freudenberg N, Vlahov D. Cities and population health. Soc Sci Med. 2005;60(5):1017-33.

37. Kaplan GA. What is the role of the social environment in understanding inequalities in health. In: Adler NE, Marmot M, McEwen BS, Stewart S, editors. Socioeconomic Status and Health in Industrial Nations. New York City, NY: New York Academy of Sciences; 1999.

38. Marmor TR, Barer ML, Evans RG. The determinants of a population's health: What can be done to improve a democratic nation's health status. In: Evans RG, Barer ML, Marmor TR, editors. Why are Some People Healthy and Others Nt?. New York: Aldine de Gruyter; 1994, pp. 217-30.

39. McKinlay JB. A case for refocusing upstream: the political economy of illness. In: Conard P, editor. The Sociology of Health and Illness. New York: St. Martin's Press; 1997.

40. McKinlay JB. The promotion of health through planned sociopolitical change: challenges for research and policy. Soc Sci Med. 1993; 36(2): 109-17.

4I. Schulz A, Northridge ME. Social determinants of health: implications for environmental health promotion. Health Educ Behav. 2004; 3 I (4):455-7I.

42. Starfield B. Pathways of influence on equity in health. Soc Sci Med. 2007;64:1355-62.

43. Coburn D, Denn K, Mykhalovskiy E, McDonough P, Robertson A, Love R. Population health in Canada: a brief critique. Am J Public Health. 2003;93(3):392-6.

44. Shy CM. The failure of American epidemiology: witness for the prosecution. Am J Epidemiol. 1997;145(6):479-84.

45. Susser M, Susser E. Choosing a future for epidemiology: I. Eras and paradigms. II. From black boxes to Chinese boxes. Am J Public Health. I 996;86:668-73; 674-8.

46. Commission on Social Determinants of Health. A Conceptual Framework for Action on the Social Determinants of Health (Draft). World Health Organization; 2007.

47. Hamlin C, Sheard S.. Revolutions in public health: 1848 , and 1998 ? $B M J$. I998;3 I7 (7I 58):587-91.

48. Rothman KH, Adami H-O, Trichopolous D. Should the mission of epidemiology include the eradication of poverty? Lancet. 1998; 352:810-3. 
49. Poole C, Rothman KH. Our conscientious objection to the epidemiology wars. J Epidemiol Community Health. 1998;52(10):613-4.

50. Poole C. Ecologic analysis as outlook and method. Am J Public Health. 1994;84(5):7 I 5-6.

51. Raphael D, Bryant T. The limitations of population health as a model for a new public health. Health Promotion Int. 2002;17(2): 189-199.

52. Rose G. Sick individuals an sick populations. Int $J$ Epidemiol. 2001;30:427-32.

53. Morabia A. History of epidemiologic methods. Soz Praventiv Med. 2001;46(I):3-4.

54. Susser M. Does risk factor epidemiology put epidemiology at risk? Peering into the future. J Epidemiol Community Health. 1998;52: 608-6II.

55. Marks HM. Epidemiologists explain Pellagra: gender, race, and political economy in the work of Edgar Sydenstricker. $J$ Hist Med Allied Sci. 2003;58(1):34-55.

56. Navarro V, Muntaner C, Borrell C, Benach J, Quiroga A, Rodriguez-Sanz $\mathrm{M}$, et al. Politics and health outcomes. Lancet. 2006;368:1033-1037.

57. Raphael D. A society in decline: the poltical, economic, and social determinants of health inequalities in the United States. In: Hofrichter R, editor. Health and Social Justice. San Francisco: Jossey Bass; 2003, pp. 57-8.

58. Globalization and Health. BioMed Central. http://www. globalizationandhealth.com/info/about/.

59. Fruedenberg N, Galea S. Corporate practices. In: Galea S, editor. Macrosocial Determinants of Population Health. New York: Springer; 2007.

6o. Sepe E, Ling PM, Glantz SA. Smooth moves: bar and nightclub tobacco promotions that target young adults. Am J Public Health. 2002; 92(3):4I4-9.

6r. Slade J. Marketing policies. In: Rabin RL, Sugarman SD, editors. Regulating tobacco. New York: Oxford University Press; 2001, pp. 72-1 Io.

62. Powell LM, Szczypka G, Chaloupka FJ, Braunschweig CL. Nutritional content of television food advertisements seen by children and adolescents in the United States. Pediatrics. 2007; I 20(3):576-83.

63. Romley JA, Cohen D, Ringel J, Sturm R. Stud Alcohol Drugs. Alcohol and environmental justice: the density of liquor stores and bars in urban neighborhoods in the United States. 2007;68(I):48-55.

64. Reed MB, Anderson CM, Vaughn JW, Burns DM. The effect of cigarette price increases on smoking cessation in California. Prev Sci. 2008;9(I):47-54. Epub 7 February 2007. 
PUTNAM AND GALEA - MACROSOCIAL DETERMINANTS OF HEALTH $\mathbf{2 8 9}$

65. Haw SJ, Gruer L. Changes in exposure of adult non-smokers to secondhand smoke after implementation of smoke-free legislation in Scotland: national cross sectional survey. BMJ. 2007;335(7619):549.

66. Davey Smith G. Cultural climate, physical climate, life and death. Int J Epidemiol. 2006;3 5(2):2 I I-2.

67. United Nations. World Urbanization Prospects: the 2005 Revision. Available at: http://www.un.org/esa/population/publications/WUP2005/ 2005wup.htm, accessed 2I April 2007. 